\title{
Should we perform systematic electrophysiological study in Steinert's disease? Abdallah Fayssoil
}

Address: Critical care medicine, Raymond-Poincare Hospital, AP-HP, University of Versailles (SQV), 92380 Garches, France

Email: Abdallah Fayssoil - fayssoil2000@yahoo.fr

Published: 18 October 2008

Journal of Cardiothoracic Surgery 2008, 3:56 doi:10.1 186/1749-8090-3-56

This article is available from: http://www.cardiothoracicsurgery.org/content/3/1/56

(c) 2008 Fayssoil; licensee BioMed Central Ltd.

This is an Open Access article distributed under the terms of the Creative Commons Attribution License (http://creativecommons.org/licenses/by/2.0), which permits unrestricted use, distribution, and reproduction in any medium, provided the original work is properly cited.
Received: 18 June 2008

Accepted: 18 October 2008

\begin{abstract}
Myotonic dystrophy type I (Steinert's disease) is a multisystem disorder with autosomal dominant inheritance. This disease is associated with the presence of an abnormal expansion of a cytosine thymine-guanine (CTG) trinucleotide repeat on chromosome $19 q / 3.3$. Because of rhythmic complications, the place for systematic electrophysiological study (EPS) has to be discussed.
\end{abstract}

\section{Manuscript}

Myotonic dystrophy type 1 (DM1 = Steinert's disease) is a multisystem disorder with autosomal dominant inheritance. This disease is caused by an unstable expansion mutation of the cytosine thymine-guanine (CTG) trinucleotide repeat situated in the 3 ' non-coding exon of a gene that encodes a serine-threonine protein kinase (DMPK). The incidence of DM1 is estimated to be $1 / 8000$ births [1]. Patients disclose features muscular disorder including myotonia, progressive muscular weakness and wasting associated to a multi-systemic disorder (cataract, hypogonadism, gastrointestinal disorders, and diabetes). Patients with DM1 have a high incidence of sudden cardiac death (SCD) because of ventricular arrhythmias and/ or complete heart block $[2,3]$. Histopathology studies disclose fibrosis in the conducting system and in the sinoatrial node associated with myocyte hypertrophy and fatty acid infiltration.

Groh WJ et al. reported in a mean follow-up period of 5.7 years, 27 sudden deaths in a study including 406 adults' patients with DM1. There is a consensus to explore symptomatic patients with DM1. Electrophysiological study (EPS) is an invasive procedure for assessing conduction abnormalities and risk of SCD (with ventricular stimulation). This procedure should be considered in case of syncope, family history of sudden death, sinus node dysfunction (sinus pause $>3$ seconds), ventricular arrhythmias and electrocardiogram (ECG) abnormalities suggesting intra or infrahissian conduction disturbances $[4,5]$ : left bundle branch block, bifascicular or trifascicular block, second or third degree atrio-ventricular (AV) block. Pacemaker implantation should be considered in symptomatic patients with conduction abnormalities. Implantable cardioverter defibrillator (ICD) has proved its efficacy to prevent SCD due to ventricular arrhythmias. An ICD implantation should be considered if spontaneous sustained VT was noted.

In asymptomatic patients, prediction of cardiac events is not easy. About asymptomatic patients, systematic EPS is performed to measure the HV interval and to implant a pacemaker before the occurrence of a high degree AV block if a first degree infra-hissian AV block has been found even if the use of the HV interval to determine the need for pacing is still controversial. Lazarus et al. proposed a prophylactic implantation of a pacemaker when the HV interval is $\geq 70 \mathrm{~ms}$ [4]. 
Non invasive tests may be used in asymptomatic patients for evaluating the risk of rhythmic complications. ECG may be useful in predicting SCD. In the study reported by Groh WJ et al. [6], MD1 patients with severe abnormality (ECG with at least one of the following features: rhythm other than sinus, PR interval of $240 \mathrm{msec}$ or more, QRS duration of $120 \mathrm{msec}$ or more, or second-degree or thirddegree AV block) were at risk for sudden death [6]. Noninvasive ambulatory ECG is another procedure for assessing asymptomatic patients. According to Sá MI. et al., non-invasive ambulatory ECG in patients with myotonic dystrophy type 1 should be performed on a regular basis, at intervals not greater than six months [7]. In a study including 36 patients with myotonic dystrophy type 1, Sá MI et al. found a high prevalence and changes between baseline and follow-up Holter ECG that justified permanent pacemaker implantation in 11 patients [7]. Heart rate turbulence may be considered as a non-invasive risk predictor of ventricular tachy-arrhythmias in Steinert's disease [8]. Hardin et al. [9] investigated the relationship between autonomic nervous system function, using holter monitoring with heart rate variability (HRV) analysis, and the clinical and genetic factors in patients with myotonic dystrophy type 1 . The authors found a decline in HRV with increasing age and the precise genetic abnormality. Signal averaged ECG is another non-invasive procedure for analysing risk stratification in asymptomatic patients. The prolongation of total QRS duration on signal averaged ECG in myotonic dystrophy is primarily related to delayed activation of the His and Purkinje tissue and not to the development of true late potentials. Some noninvasive test can predict the occurrence of AV block with the same efficacy than HV measurement to suppress systematic electrophysiological study. According to Babuty D et al. [10], association of QRS duration $\geq 100 \mathrm{~ms}$ with low amplitudes signals $(<40 \mu \mathrm{V}) \geq 36 \mathrm{~ms}$ may identify patients with an abnormal HV interval with good sensitivity (80\%) and specificity (83. 3\%). Genetic analysis is also a non-invasive assessment of cardiac risk. The severity of cardiac myopathy in DM 1 seems to be correlated with age and CTG repeat length [11]. In the study reported by Babuty D. et al., the size of the DNA mutation was longer in the abnormal HV interval group than in the normal HV interval group (3.5(1.8) vs 2.2 (1.0) kb, p < 0.02) [10]. For analysing the risk of SCD in asymptomatic patients, there is not a consensus for performing systematic ventricular stimulation. Moreover, even in symptomatic patients it can be difficult to base the decision of ICD implantation on a positive EPS, given the possibility of a false positive result. HV prolongation could be also an indirect marker of risk of ventricular tachycardia.

\section{References}

I. Mathieu J, Allard P, Potvin L, Prévost C, Bégin P: A I0-year study of mortality in a cohort of patients with myotonic dystrophy. Neurology 52(8): 1658-62. 1999 May 12
2. Phillips MF, Harper PS: Cardiac disease in myotonic dystrophy. Cardiovasc Res 1997, 33(I): 13-22.

3. Hawley RJ, Milner MR, Gottdiener JS, Cohen A: Myotonic heart disease: a clinical follow-up. Neurology 1991, 4I(2 (Pt I)):259-62.

4. Lazarus A, Varin J, Ounnoughene Z, Radvanyi H, Junien C, Coste J, Laforet P, Eymard B, Becane HM, Weber S, Duboc D: Relationships among electrophysiological findings and clinical status, heart function, and extent of DNA mutation in myotonic dystrophy. Circulation 99(8): 104I-6. 1999 Mar 2

5. Pelargonio G, Dello Russo A, Sanna T, De Martino G, Bellocci F: Myotonic dystrophy and the heart. Heart 2002, 88(6):665-70.

6. Groh WJ, Groh MR, Saha C, Kincaid JC, Simmons Z, Ciafaloni E, Pourmand R, Otten RF, Bhakta D, Nair GV, Marashdeh MM, Zipes DP, Pascuzzi RM: Electrocardiographic abnormalities and sudden death in myotonic dystrophy type I. N Engl J Med 358(25):2688-97. 2008 Jun 19

7. Sá MI, Cabral S, Costa PD, Coelho T, Freitas M, Gomes JL: Ambulatory electrocardiographic monitoring in type 1 myotonic dystrophy. Rev Port Cardiol 2007, 26(7-8):745-53.

8. Casella M, Dello Russo A, Pace M, Pelargonio G, lerardi C, Sanna T, Messano L, Bencardino G, Valsecchi S, Mangiola F, Lanza GA, Zecchi $P$, Crea $F$, Bellocci $F$ : Heart rate turbulence as a noninvasive risk predictor of ventricular tachyarrhythmias in myotonic dystrophy type I. J Cardiovasc Electrophysiol 2006, I 7(8):87| I-6.

9. Hardin BA, Lowe MR, Bhakta D, Groh WJ: Heart rate variability declines with increasing age and CTG repeat length in patients with myotonic dystrophy type I. Ann Noninvasive Electrocardiol 2003, 8(3):227-32.

10. Babuty D, Fauchier L, Tena-Carbi D, Poret P, Leche J, Raynaud M, Fauchier JP, Cosnay $P$ : Is it possible to identify infrahissian cardiac conduction abnormalities in myotonic dystrophy by non-invasive methods? Heart 1999, 82(5):634-7.

II. Groh W], Lowe MR, Zipes DP: Severity of cardiac conduction involvement and arrhythmias in myotonic dystrophy type I correlates with age and CTG repeat length. J Cardiovasc Electrophysiol 2002, I3(5):444-8.

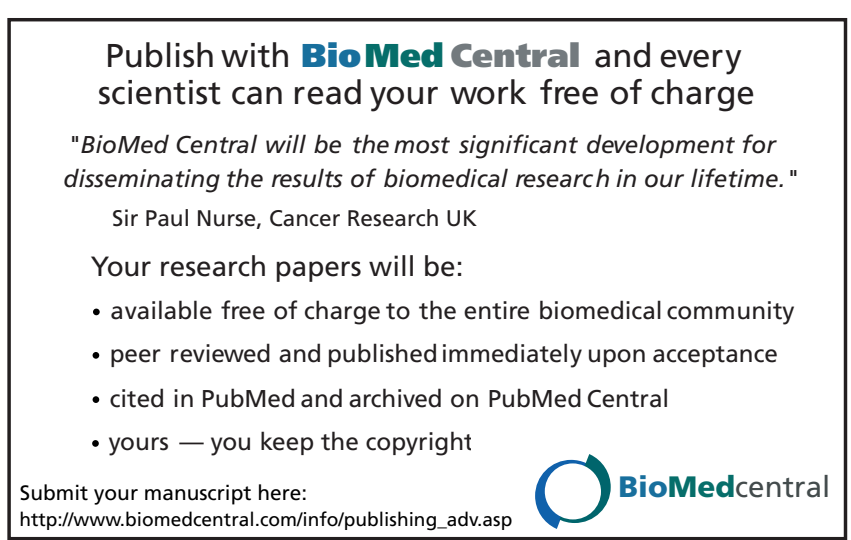

